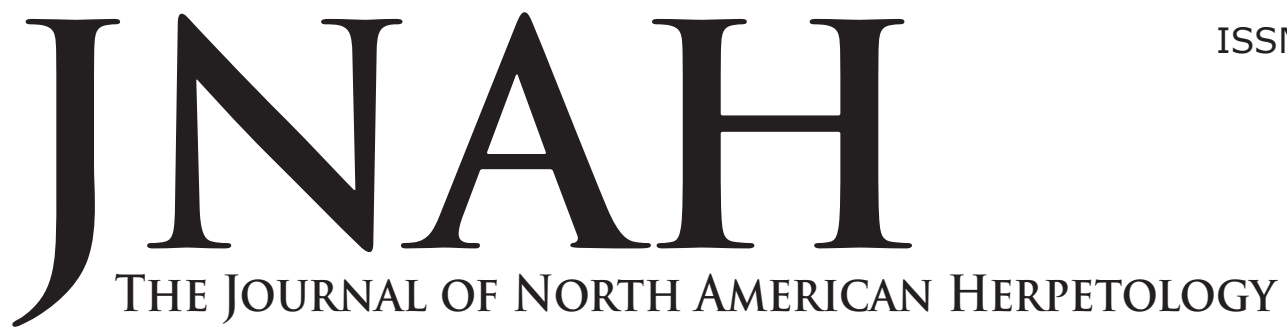

ISSN 2333-0694

Volume 2021, Number 1

June 2021

journals.ku.edu/jnah

\title{
SOME THOUGHTS ON INTERSPECIFIC MANDIBULAR MORPHOLOGY IN FOSSIL AND MODERN ALLIGATOR
}

\author{
JEREMY B. STOUT ${ }^{1}$ \\ ${ }^{1}$ The Nature Center at Steele Creek Park, 80 Lakeshore Drive, Bristol, Tennessee, 37620 USA, \\ jstout@bristoltn.org https://orcid.org/0000-0001-8747-3561.
}

\begin{abstract}
Alligator is diagnosed in the fossil record using discrete morphological characters. These characters are used with systematic analyses to determine hypothetical phylogenetic relationships. Examined here are two such characters for applicability in fossil species determination and relationship. One is the curvature of the dentary between the fourth and tenth alveoli (observed in several taxa), while the other is a further investigation into the anterior extent of the splenial (in modern Alligator mississippiensis and the early Pleistocene $A$. hailensis). In a small sample size, the curvature of the dentary exhibits wide variability in character states both intraspecifically and interspecifically, bringing into question its utility in fossil crocodylian systematic applications. The anatomy of the anterior extent of the splenial is phylogenetically informative, and a new method for inferring its presence as a basal or derived state (as a scar on the dentary) is described.
\end{abstract}

Key Words: Alligator, skeletal morphology, mandibular morphology, phylogenetics

\section{INTRODUCTION}

Alligator has historically been used for nearly any blunt-snouted (brevirostrine) crocodylomorph (especially if the lower jaws occlude lingually with the upper), to erroneously include modern caimans (e.g. Duméril and Bibron, 1836, and Strauch, 1866), Paleogene European alligatoroids (Wood, 1846), and many more inappropriate generic assignments (Malone, 1979). The genus has been greatly constrained in its modern application via Brochu, 1999 and 2004, such that species within the genus possess the following shared osteological traits:

- The lingual foramen for the articular artery and alveolar nerve lies on the surangular/articular suture of the lower jaw: corrected in Whiting and Hastings (2015); the original stated location (in Brochu, 1999) "on the surangular/angular suture" appears to be an enduring lapsus calami in some works.

- The external narial opening is bisected by the nasals.

- The medial process of the prefrontal pillar is expanded anteroposteriorly.

- The premaxillary surface lateral to the naris exhibits a deep notch.

- The internal choana contains a septum that projects outward.

\section{Problematic Characters}

Phylogenetic approaches employed in the past two decades using mostly osteological characters have greatly expanded the current understanding of crocodylian systematics and evolution (based largely on Brochu, 1999). However, some characters are questionable as phylogenetic indicators due to variable character states intraspecifically, such as that found in the frontoparietal suture of modern Alligator mississippiensis (Whiting et al., 2016).

One character used in modern work is the relative curvature of the dentary between the fourth and tenth alveoli (when viewed laterally and counted from anterior to posterior). Most modern and fossil crocodylians exhibit slight curvature along this length, though some (such as the early Miocene Alligator olseni) are scored as possessing deep curvature, while others (such as the longirostrine gharial Gavialis gangeticus) are interpreted as linear (Brochu, 1999). Despite the obvious problem of subjectivity in evaluating "slight" versus "deep" there also appears to be a large degree of variability within individuals of the extinct Alligator hailensis (Stout, 2020) and modern A. mississippiensis (pers. obs.). Snyder (2007) suggested some minor changes in defining the character and rescored Alligator olseni as "slightly curved" though recent work (such as Cossette and Brochu, 2018) continues to consider $A$. olseni as possessing 
a deeply curved dentary. This character is considered by Brochu (2004) as an apomorphy for Alligatorinae.

Additionally, some characters that are phylogenetically and taxonomically informative might only rarely be preserved in the fossil record due to their fragile nature. This is especially true of the anterior portion of the splenial in derived taxa (Stout, 2020). The splenial is a bone found in the lower jaw of many tetrapods (Romer, 1956), and occurs in crocodylians as a laterally thin flange making up much of the lingual margin of the Meckelian canal (Iordansky, 1973). It acts as a structural component of the mandibular symphysis in some crocodylians, but is separated posteriorly from the symphysis in others. In derived Alligator, the splenial does not participate in the mandibular symphysis and shows either presence or absence of the anterior foramen intermandibularis oralis (an informative diagnostic feature in Alligator species, Brochu, 1999). Stout (2020) described Alligator hailensis partially on the basis of an enlarged and autapomorphic anterior portion of the splenial preserved in a single individual, but suggested that the expanded splenial might be detectable as a scar on the dentary at the $5^{\text {th }}$ alveolus (the approximate location of the preserved autapomorphic foramen), even if not preserved directly.

Tested here is the utility of two abovementioned mandibular osteological traits in fossil Alligator species: the relative curvature of the dentary between the fourth and tenth alveoli, and the relative height of the splenial at the fifth alveolus. The aim of this study is to offer observations (corroborated by data) about these characteristics, not make comprehensive assertions about their efficacy in species diagnosis or phylogenetic analyses.

\section{MATERIALS AND METHODS \\ Institutional Abbreviations}

ETMNH: East Tennessee State University Museum of Natural History, East Tennessee State University, Johnson City, Tennessee. FLMNH: Florida Museum of Natural History, University of Florida (UF), Gainesville, Florida. SCPNC: The Nature Center at Steele Creek Park, Bristol, Tennessee.

\section{Dentary Curvature Analysis}

To attempt to better define the curvature of the dentary between the fourth and tenth alveoli, linear mea-

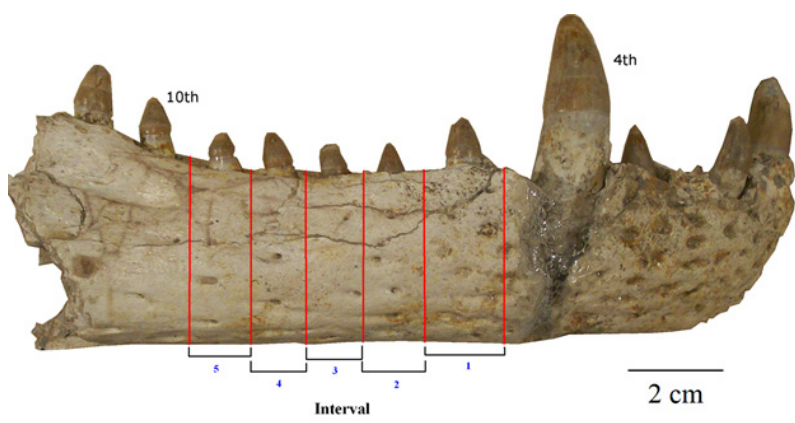

Fig. 1. Location of measurements taken (red lines) and intervals shown for dentary curvature analysis. Model specimen is the Alligator hailensis holotype (UF 224688) right dentary but was not used in the analysis due to taphonomic damage and subsequent reconstruction. Percent difference was calculated along each interval and added to reflect a total change in curvature of the dentary across the range.

surements were taken of eight mature individuals representing seven species (living and extinct) across the three extant crocodylian families (Alligatoridae, Crocodylidae, Gavialidae). These were then compared (outlined below), with the assumption that character variability paired with interspecific overlap should compromise the diagnostic quality of the character. The data are not meant to provide statistically significant analyses but rather represent a limited sample of available specimens to test the character, which is consistent with that typically available from the fossil record (small sample sizes).

The curvature of the dentary between the fourth and tenth alveoli in crocodylians occurs as a narrowing of the dorsal surface of the dentary towards a constriction in the middle of the range. It is usually most narrow at the eighth alveolus in Alligator (pers. obs.). Straight-line distances were measured with a Vernier caliper between the alveoli along this range (inter-alveolar midpoints). The percent difference of each interval between each measurement was calculated (as $\left(\mid\left(\right.\right.$ val $\left.\left._{1}-\left.v_{2}\right|_{2}\right) \mid\right) /$ mean of $\mathrm{val}_{1}$ and $\left.\mathrm{val}_{2}\right) * 100$ ), and then added to reflect a total percentage of change in height (i.e. curvature) along the range. The assumption of this test is that greater dentary curvature should appear as greater percent total change. Calculation of percent difference (instead of

Table 1. Inter-alveolar midpoint height (in millimeters). Straight line measurements of dentary height were taken with a Vernier caliper between the fourth and tenth alveoli. Only right dentaries were used, except where noted.

\begin{tabular}{|c|c|c|c|c|c|c|}
\hline \multicolumn{7}{|c|}{ Inter-Alveolar Midpoint (in mm) } \\
\hline Taxon & 4th-5th & 5th-6th & 6th-7th & 7th-8th & 8th-9th & 9th-10th \\
\hline Crocodylus porosus ETMNH-Z 208 & 15 & 14 & 14.5 & 15 & 16 & 19 \\
\hline $\begin{array}{l}\text { Crocodylus niloticus } \\
\text { ETMNH-Z } 6921\end{array}$ & 57 & 54 & 50.5 & 48.8 & 51 & 57.2 \\
\hline $\begin{array}{l}\text { Gavialis gangeticus } \\
\text { ETMNH-Z } 6923\end{array}$ & 19.75 & 20 & 20.75 & 21.5 & 22.5 & 22.75 \\
\hline $\begin{array}{l}\text { Tomistoma schlegelii } \\
\text { ETMNH-Z } 6924\end{array}$ & 18.5 & 18 & 17.5 & 19 & 19.5 & 19.25 \\
\hline $\begin{array}{l}\text { Alligator mississippiensis } \\
\text { ETMNH-Z } 265\end{array}$ & 48 & 43 & 39 & 36 & 38.5 & 39 \\
\hline Alligator hailensis UF 162517 & 47.5 & 42.2 & 38 & 37.5 & 37.4 & 41.1 \\
\hline Alligator hailensis UF 162533 (left) & 28.8 & 27.4 & 26.9 & 27.1 & 27.9 & 28 \\
\hline Alligator olseni UF 143667 (left) & 23.3 & 20.4 & 17.1 & 17.7 & 17.2 & 17.5 \\
\hline
\end{tabular}




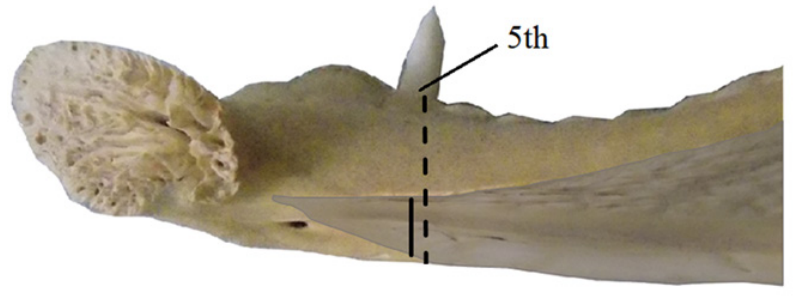

$2 \mathrm{~cm}$

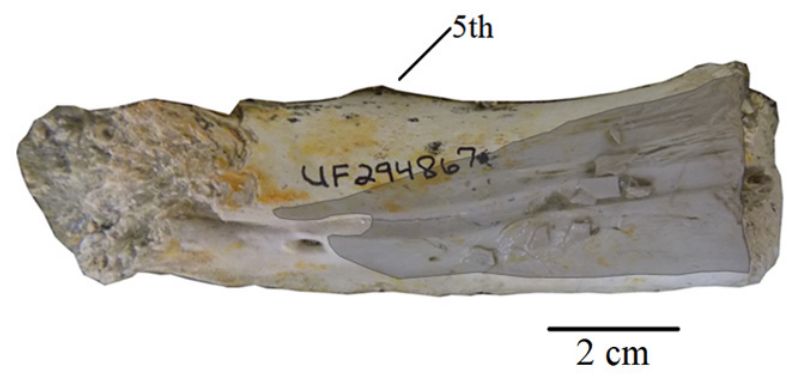

Fig. 2. Relative height of the splenial at the $5^{\text {th }}$ dentary alveolus (as inferred as a scar on the dentary). Modern Alligator mississippiensis (ETMNH-Z 3367) is shown at top, with locations of measurements taken of all individuals shown as dashed line (dentary height) and solid line (splenial height). The early Pleistocene A. hailensis (UF 294867) is shown at bottom. The missing splenial in each is shadow outlined. The inferred shape of the splenial in A. hailensis is based on Stout (2020).

raw measurements) also controlled for the varying size of the taxa and individuals used in the analysis (Figure 1 ). For uniformity right dentaries were preferred, though left dentaries were used in UF 162533 (Alligator hailensis) and UF 143667 ( $A$. olseni) due to their better preservation.

Taxa used in the analysis were the extinct alligators Alligator olseni and A. hailensis (FLMNH), modern A. mississippiensis, the crocodiles Crocodylus porosus and $C$. niloticus, the gharial Gavialis gangeticus and the False Gharial Tomistoma schlegelii (ETMNH). Only ontogenetically mature individuals (as determined by specimen size) of all taxa were chosen for this analysis to control for possible developmental bias (Table 1 ).

\section{Anterior Splenial Height}

To test for the inference of a basal or derived state in the anterior portion of the splenial in Alligator, mandibular data from specimens from modern $A$. mississippiensis in the collections of ETMNH and SCPNC were collected and compared with the preserved material of $A$. hailensis. The relative height of the splenial was determined by measuring a straight-line height (with Vernier calipers) of either the splenial directly, or as a scar on the dentary, at the $5^{\text {th }}$ dentary alveolus (when counted from the anterior-most position). These were then compared (as a proportion) with the overall height of the dentary at the same location (Figure 2).

Both right and left mandibulae were used in this analysis to allow for comparison of possible variation within individuals. Data from individuals of all available sizes were collected to test for ontogenetic variation within the character. Percent calculation of the height of the splenial was calculated, along with a five-number summary (minimum value, lower quartile, median value, upper quartile, and maximum value). The five-number summary is used here as an illustrative tool to show the data spread for each species. Data are found in Table 3 and results in Figure 4.

\section{RESULTS}

Table 1 shows the height (in $\mathrm{mm}$ ) of the lower jaw between each of the alveoli (inter-alveolar midpoint) between the $4^{\text {th }}$ and $10^{\text {th }}$ alveoli. From these measurements, percent difference from each alveolar midpoint to the next was calculated and each of these intervals were added together to reflect the total change of dentary curvature across the range. Results are shown in Table 2 and Figure 3.

Table 3 shows the dentary and splenial height (including percent calculation) at the $5^{\text {th }}$ alveolus for Alligator mississippiensis and $A$. hailensis. Box plots of the five-number summary from the data for each species do not overlap and are shown in Figure 4.

\section{DISCUSSION}

The results show that, within a small sample, the curvature of the dentary between the fourth and tenth alveoli fails to provide diagnostic utility among species and individuals tested due to the overlap in character states,

Table 2. Percent difference along each interval between the $4^{\text {th }}$ and $10^{\text {th }}$ dentary alveoli. Each interval is shown in Figure 1 . Total change represents the total percent change across the intervals listed. Taxa were chosen to compare all three possible character states as outlined in Brochu (1999) - linear, slightly curved, and deeply curved.

\begin{tabular}{|l|c|c|c|c|c|c|}
\hline \multicolumn{3}{|c|}{ Interval Percent Difference } & \multicolumn{1}{|c|}{$\mathbf{5}$} & Total Change \\
\hline Taxon & $\mathbf{1}$ & $\mathbf{2}$ & $\mathbf{3}$ & $\mathbf{4}$ & $\mathbf{5}$ & $\mathbf{3 7 . 4}$ \\
\hline Crocodylus porosus ETMNH-Z 208 & 6.9 & 3.5 & 3.4 & 6.5 & 17.1 & $\mathbf{3 1 . 4}$ \\
\hline Crocodylus niloticus ETMNH-Z 6921 & 5.4 & 6.7 & 3.4 & 4.4 & 11.5 & $\mathbf{1 4 . 3}$ \\
\hline Gavialis gangeticus ETMNH-Z 6923 & 1.2 & 3.9 & 3.6 & 4.5 & 1.1 & $\mathbf{1 7 . 6}$ \\
\hline Tomistoma schlegelii ETMNH-Z 6924 & 2.7 & 2.8 & 8.2 & 2.6 & 1.3 & $\mathbf{3 6 . 7}$ \\
\hline Alligator mississippiensis ETMNH-Z 265 & 10.9 & 9.8 & 8 & 6.7 & 1.3 & $\mathbf{3 3 . 3}$ \\
\hline Alligator hailensis UF 162517 & 11.8 & 10.5 & 1.3 & 0.3 & 9.4 & $\mathbf{1 0 . 8}$ \\
\hline Alligator hailensis UF 162533 & 5 & 1.8 & 0.7 & 2.9 & 0.4 & $\mathbf{3 9}$ \\
\hline Alligator olseni UF 143667 & 13.3 & 17.6 & 3.5 & 2.9 & 1.7 & \\
\hline
\end{tabular}


Table 3. Relative height of splenial at the $5^{\text {th }}$ dentary alveolus. Right $(R)$ and left $(L)$ are denoted at the end of the catalog number. t denotes a specimen with a missing splenial (measurement taken from the scar exposed on the dentary).

\begin{tabular}{|c|c|c|c|c|}
\hline & Specimen & $\begin{array}{l}\text { Dentary Height at 5th } \\
\text { Alveolus }(\mathrm{mm})\end{array}$ & $\begin{array}{l}\text { Splenial Height at } 5 \text { th } \\
\text { Alveolus }(\mathrm{mm})\end{array}$ & $\begin{array}{l}\text { Splenial \% } \\
\text { Height }\end{array}$ \\
\hline \multirow[t]{28}{*}{ Alligator mississippiensis } & SCPNC154R & 12.9 & 4.1 & 0.32 \\
\hline & SCPNC154L & 13.6 & 4.6 & 0.34 \\
\hline & ETMNH-Z 6920R & 30.9 & 8.0 & 0.26 \\
\hline & ETMNH-Z 265R + & 44.9 & 11.9 & 0.27 \\
\hline & ETMNH-Z 265L & 46.1 & 12.9 & 0.28 \\
\hline & ETMNH-Z 7209L & 17.9 & 6.5 & 0.36 \\
\hline & ETMNH-Z 3236L† & 26.1 & 8.9 & 0.34 \\
\hline & ETMNH-Z 7208R & 32.0 & 9.2 & 0.29 \\
\hline & ETMNH-Z 7208L & 32.7 & 9.8 & 0.30 \\
\hline & ETMNH-Z 3150R† & 26.1 & 7.2 & 0.28 \\
\hline & ETMNH-Z 3150L & 24.3 & 10.8 & 0.44 \\
\hline & ETMNH-Z 3250L & 18.8 & 5.1 & 0.27 \\
\hline & ETMNH-Z 509R & 24.1 & 6.2 & 0.26 \\
\hline & ETMNH-Z 509L + & 23.9 & 7.0 & 0.29 \\
\hline & ETMNH-Z 3366R & 29.3 & 6.4 & 0.22 \\
\hline & ETMNH-Z 3366L & 28.8 & 8.6 & 0.30 \\
\hline & ETMNH-Z 3369R† & 20.8 & 7.9 & 0.38 \\
\hline & ETMNH-Z 3369L† & 21.1 & 7.4 & 0.35 \\
\hline & ETMNH-Z 7205L & 18.9 & 4.9 & 0.26 \\
\hline & ETMNH-Z 7204R & 24.1 & 7.7 & 0.32 \\
\hline & ETMNH-Z 7204L + & 24.4 & 8.3 & 0.34 \\
\hline & ETMNH-Z 3368R† & 25.3 & 8.0 & 0.32 \\
\hline & ETMNH-Z 3370R & 21.0 & 5.9 & 0.28 \\
\hline & ETMNH-Z 3370L & 20.3 & 4.8 & 0.24 \\
\hline & ETMNH-Z 3367R† & 28.5 & 8.9 & 0.31 \\
\hline & ETMNH-Z 3367L† & 28.6 & 9.4 & 0.33 \\
\hline & ETMNH-Z 3036R† & 33.9 & 8.9 & 0.26 \\
\hline & ETMNH-Z 3036L† & 35.1 & 9.4 & 0.27 \\
\hline \multirow[t]{4}{*}{ Alligator hailensis } & UF $162533 \mathrm{~L}$ & 28.4 & 19.4 & 0.68 \\
\hline & UF $162532 \mathrm{R}+$ & 25.0 & 13.4 & 0.54 \\
\hline & UF 224688R† & 44.9 & 30.6 & 0.68 \\
\hline & UF $294867 \mathrm{R} \dagger$ & 28.0 & 17.3 & 0.62 \\
\hline
\end{tabular}

and that Alligator spp. is capable of occupying all three character states. Alligator hailensis shows wide polymorphism of dentary curvature within the single species, and "slightly curved" Crocodylus porosus (ETMNH-Z 208) approaches "deeply curved" $A$. olseni (UF 143667) in its curvature. Simple rescoring of character data for some species (such as $A$. olseni via Snyder, 2007) might mitigate some of these issues, though intraspecific variation (as in $A$. hailensis) would continue to be problematic.
Most crocodylians do exhibit "slight curvature" along this range (Brochu, 1999), though the definition and application of the character are further brought into question. The method described herein is simple and scalable, and could be applied to collections of modern and fossil crocodylians for more significant results.

A polymorphic character state in a single taxon does not necessarily preclude its phylogenetic significance in others (contra Whiting et al., 2016), and workers should 


\section{Percent Dentary Change Between 4th and 10th Alveoli}

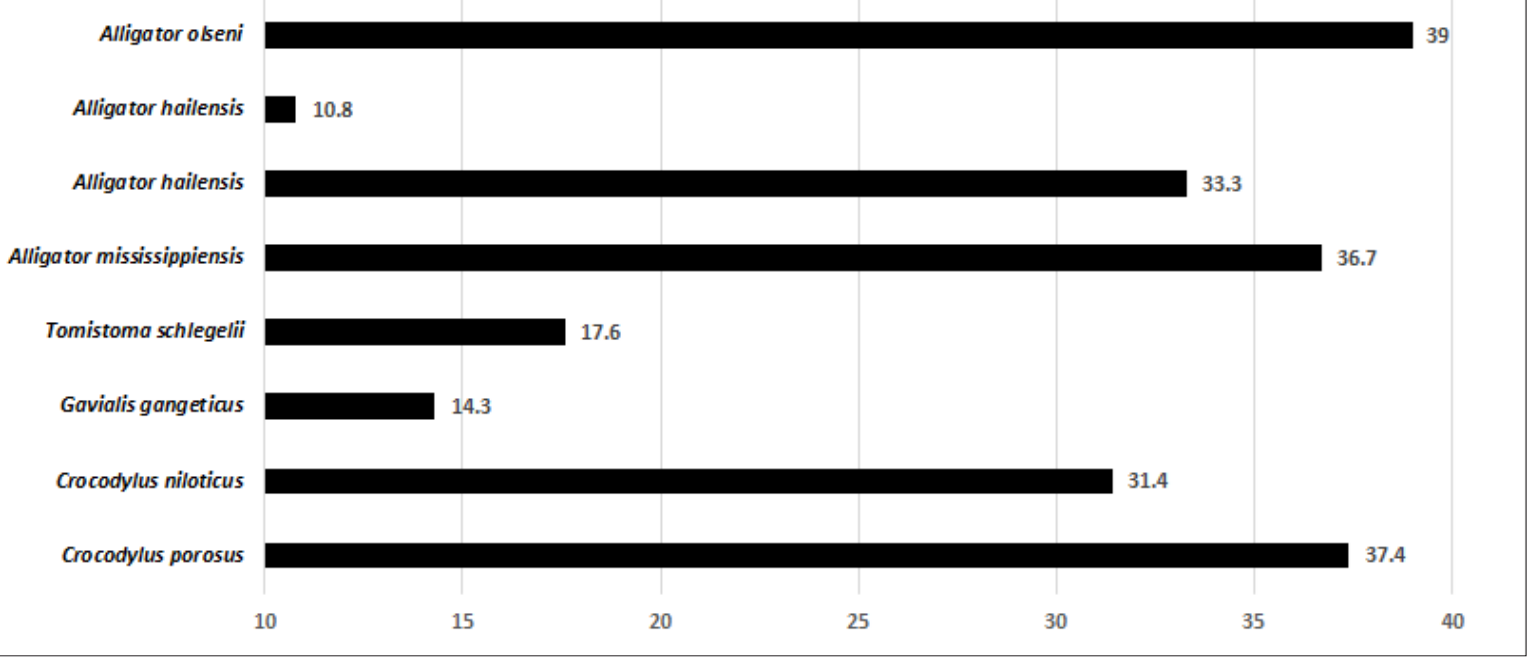

Figure 3. Total percent difference (change) between the fourth and tenth alveoli of modern and fossil crocodylians. Alligator olseni is considered as having a "deeply curved" dentary whereas Gavialis and Tomistoma are scored as "linear". All other taxa shown are scored as "slightly curved" in previous studies. Overlap across taxa and character states shows that the character states (as defined) are not diagnostic across taxa or within a single taxon (as with $A$. hailensis).

be cautious to not assume phenotypic plasticity in a derived taxon is also true for basal taxa. However, some characters (like the relative curvature of the dentary) that are intraspecifically polymorphic should perhaps be reconsidered or redefined for use in phylogenetic and taxonomic applications.

As suggested by Stout (2020), the relative height of the splenial is detectable without preservation of its anterior extent and can offer some insight into the character state housed there. The range of observed relative splenial height in Alligator mississippiensis (across

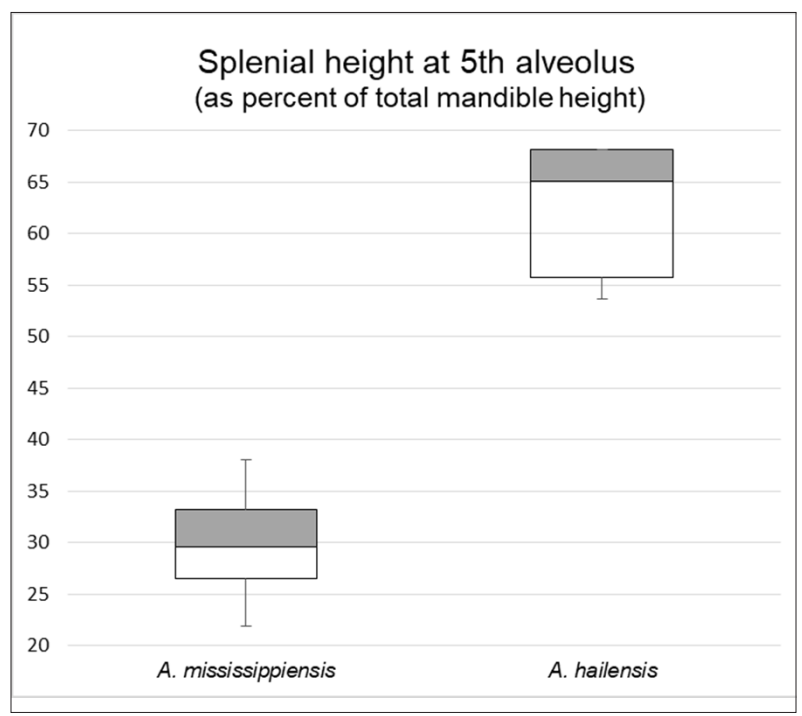

Figure 4. The relative height of the splenial at the $5^{\text {th }}$ alveolus in Alligator mississippiensis and A. hailensis, represented by a box and whisker plot graph of the five number summary (minimum value, lower quartile, median value, upper quartile, and maximum value). Data are found in Table 3. diverse sizes of individuals) does not overlap with the closely-related $A$. hailensis (Figure 4). This suggests that the relative height of the splenial is an ontogenetically stable measurement, and is reliable in absence of a preserved splenial.

These results are especially compelling when comparing right and left dentaries of the same individuals, which vary little from each other. Most splenial heights varied less than 10 percent between right and left in these data. The largest discrepancy was observed in ETMNH-Z 3150 (the right splenial was absent but its scar made up 62 percent that seen in the preserved splenial on the left). Whether or not the splenial was present had little bearing on the overall measurement. This finding allows for extrapolation where a specimen contains one splenial but not the other (such as ETMNH-Z 7204), or in fossil specimens where one side is preserved but not the other.

While interpreting the splenial scar on the dentary does not explicitly show presence, absence, or incomplete closure of the anterior foramen intermandibularis oralis, its relative height greater than 50 percent is consistent with that seen in the basal taxon (Alligator hailensis, Stout, 2020), and according to these data, is not expected to be regularly greater than 40 percent in A. mississippiensis. This method should be tested with other taxa and used with specimens in which the anterior splenial is not preserved (such as the Moss Acres Racetrack Alligator, A. cf. A. mefferdi, Snyder, 2007) as a cursory method for determining the likely character state.

Better understanding of interspecific variation within the genus will strengthen phylogenetic analyses, help define taxonomic relationships and offer clues regarding the biogeography of Alligator and its dispersal into Asia. Opting for more discrete versus gradational character states might better provide the phylogenetic signal to discern among crown group Alligator (and Crocodylia in general). Further testing of these (and all characters) is recommended. 


\section{ACKNOWLEDGMENTS}

The author wishes to thank B. Compton (ETMNH), J. Bourque and R.C. Hulbert Jr. (FLMNH) for their hospitality during this research. Discussions with J. McMeen and the comments from two anonymous reviewers were greatly appreciated.

\section{LITERATURE CITED}

Brochu, C.A. 1999. Cranial morphology of Alligator mississippiensis and phylogeny of Alligatoroidea. Memoir 6, supplement to Journal of Vertebrate Paleontology $19(2), 100 \mathrm{pp}$.

Brochu, C.A. 2004. Alligatorine phylogeny and the status of Allognathosuchus Mook, 1921. Journal of Vertebrate Paleontology 24(4): 857-873.

Cossette, A.P., and C.A. Brochu. 2018. A new specimen of the alligatoroid Bottosaurus harlani and the early history of character evolution in the alligatorids. Journal of Vertebrate Paleontology 38(4): 22 p.

Duméril, A.M.C. and G. Bibron. 1836. Érpetologie Générale, ou Histoire Naturelle Compléte des Reptiles. Paris: Libraire Encyclopedique de Roret, 518 pp. [In French]

Iordansky, N.N. 1973. The skull of the Crocodilia. In Biology of the Reptilia, Volume 4. C. Gans and T. Parsons (eds). Academic Press (London): 201-260.

Malone, B. 1979. The systematics, phylogeny and paleobiology of the genus Alligator. Doctoral dissertation, City University of New York, 159 pp.
Romer, A.S. 1956. Osteology of the Reptiles. University of Chicago Press, Chicago, Illinois, 772 pp.

Snyder, D. 2007. Morphology and systematics of two Miocene alligators from Florida, with a discussion of Alligator biogeography. Journal of Paleontology 81(5): 917-928 pp.

Stout, J.B. 2020. New early Pleistocene Alligator (Eusuchia: Crocodylia) from Florida bridges a gap in Alligator evolution. ZooTaxa 4868(1): 41-60.

Strauch, A. 1866. Synopsis der gegenwärtig lebenden Crocodiliden. Eggers \& Schmitzdorff. [In German]

Whiting, E.T., and A.K. Hastings. 2015. First fossil Alligator from the late Eocene of Nebraska and the Late Paleogene record of alligators in the Great Plains. Journal of Herpetology 49(4): 560-569.

Whiting, E.T., Steadman, D.W., and K.A. Vliet. 2016. Cranial polymorphism and systematics of Miocene and living Alligator in North America. Journal of Herpetology 50(2): 206-215.

Wood S. 1846. On the discovery of an alligator and of several new Mammalia in the Hordwell Cliff; with observations upon the geological phenomena of that locality. The London Geological Journal, and Record of Discoveries in British and Foreign Paleontology 1: $1-7$. 